\title{
Analysis of multipolar generators operating efficiently in low- speed water and wind flows using ANSYS MAXWELL program
}

\author{
Nasullo Sadullaev ${ }^{1, *}$, Shukhrat Nematov $^{1}$, and Farid Sayliev ${ }^{1}$ \\ ${ }^{1}$ Energy-audit Department, Bukhara Engineering-Technological Institute, 200100 Bukhara, Uzbekistan
}

\begin{abstract}
The article analyses generators generating efficient electricity at low speed water and wind flows. High rotating speed generators are used in wind farms and micro-hydropower. Reduction gears are used to provide the generators with the required number of rotations. The use of reduction gears in the power system leads to a decrease in the efficiency of the system and additional capital costs. The study analyzed multipolar synchronous generators. Both generators used a permanent magnet to generate electromotive force, and the generators are distinguished by the radial and axial placement of the permanent magnets. In order to analyze the generators, virtual models were created and analyzed in the Ansys Maxwell program. The Ansys Maxwell program is used to analyze electric machines in the electromagnetic field. The use of these programs in determining the optimal size of new devices is of great importance in saving time and improving cost-effectiveness.
\end{abstract}

\section{Introduction}

One of the best ways to overcome the energy crisis in the use of traditional energy sources in the world today is to increase the share of renewable energy sources in energy production. The use of renewable energy sources takes into account their types, the potential of the region, the cost of energy produced and many other factors. Hydropower has long been widely used to generate electricity from renewable energy sources. The reason for this is that the energy flows generated by water are somewhat flat compared to other types of energy sources. For example, a stream of water flows in a straight line relative to a stream of wind. Another effective aspect of the use of hydropower is the density of water (the density of water flow is about 843 times greater than the airflow).

One of the current problems in the use of microhydropower in the country is the lack of production of generators that operate efficiently at low speed water flows. The production of these generators will play an important role in increasing the share of water and wind energy in our region.

A group of researchers studied wind speed data and an analysis of the potential of wind energy in the Bukhara region [1,2]. The values of specific power and energy at different heights were determined by extrapolarization. In 2016, it was found that the average wind speed at the intersection of months was $3,404 \mathrm{~m} / \mathrm{s}$ per year, and the wind direction was mainly north. The specific power values obtained from the wind current at a height of $10 \mathrm{~m}$ using the Weibull distribution function are given in months. The highest specific power in June was $93,18 \mathrm{~W} / \mathrm{m} 2$. Average annual power density 40,98
$\mathrm{W} / \mathrm{m}^{2}$. The annual specific energy is $359,56 \mathrm{kWh} / \mathrm{m}^{2}$. The average wind speed was $3,404 \mathrm{~m} / \mathrm{W} / \mathrm{s}$ at $10 \mathrm{~m}, 4,4$ $\mathrm{m} / \mathrm{s}$ at $50 \mathrm{~m}$ and $4,9 \mathrm{~m} / \mathrm{s}$ at $100 \mathrm{~m} \mathrm{[3,4]}$.

The study showed that for low-power consumers, the use of low-speed electric generators could be effective when using wind power plants at a height of up to $10 \mathrm{~m}$. In addition, most of the territory of republic is located on plains and does not have large pressure streams. Therefore, in many areas, the speed of water flows is low, which requires the use of reduction devices in the production of electricity from them. The use of multipolar small-sized electrical generators plays an important role in the efficient use of low-speed water and wind power.

Due to the complex topology and high dimensionality of the designs of various electrical machines and power supply devices, computation of a 3D transient solution usually takes a huge amount of time to reach a steady state, especially for devices with a large electromagnetic time constant. Version 15.0 introduces a new algorithm that reduces simulation time by at least five times. This option is available in transient solvers using an external circuit connection. The new AC_Model element modifies the currents in the windings before the start of each period without interrupting the calculation. ANSYS Maxwell is rapidly evolving; high-performance solvers with high accuracy and maximum speed calculate static, harmonic electromagnetic and electric fields, as well as transients in field problems. The user is provided with a huge toolkit and a modern postprocessor for calculating and optimizing electromechanical devices based on the analysis of a virtual model. ANSYS Maxwell makes it easy to work with electromechanical tasks $[5,6]$.

\footnotetext{
* Corresponding author: mrshuxa@mail.ru
} 


\section{Methodology}

The production of electricity using low wind and water flows is a rather complicated process. Since many electrical generators generate high rated speeds, additional reducing gears are required. The use of reducing gears leads to a decrease in system efficiency and an increase in capital costs. To create an efficient generator for low-speed wind and water currents, it is necessary to determine its optimal size [7-9]. At the next stage, a virtual model is created based on its optimal dimensions; its electromagnetic properties and resistance to mechanical stress are checked. After analyzing the results, a copy of the device is created. If the device is created without justification and insufficient analysis at the above stages, this will lead to an increase in the time and cost of manufacturing the device. In his research, Ansys Maxwell creates and simulates a virtual model of a bipolar permanent magnet generator of two types. The purpose of the virtual model analysis is to virtually observe the processes occurring in both generators, observe the magnetic induction lines of force generated in them and compare the output parameters. By doing such research, researchers can get many impressions from creating a new model of a generator that works effectively in conditions of low wind and water currents.

During the design process, the dimensions of all parts of the electric machine are entered (the outer and inner diameters of the stator, the number of poles, the number of grooves and the dimensions of the coil diameter and the connection group are entered). The ANSYS RMxprt program in the Maxwell program is a special program for the design of 19 types of electric motors, the program is characterized by the ease of entering the parameters used in the design of motors. It is much more convenient to use the materials in the program library to show what material the machines are made of, as it includes the properties of the materials i.e. magnetic permeability, resistance, density and a number of other properties.

The calculation used the ANSYS RMxprt program from the Maxwell program, which initially selected the generator we wanted to calculate from the electric motors or generators offered by the program, i.e. the synchronous generator shown in the first column (fig-1).

In step 1, the multipolar synchronous generator was designed in the Ansys Maxwel program and the basic parameters of the machine were entered i.e. number of poles $=2$, rotor position $=$ external rotor, speed $=250$ $\mathrm{rpm}$, control method = alternating current $(\mathrm{AC})$, then the stator dimensions on the inside of the machine section were entered, i.e. the outer diameter of the stator $=550$ $\mathrm{mm}$, the inner diameter of the stator $=380 \mathrm{~mm}$ and other additional parameters, the rotor parameters after the stator dimensions were entered and a $10 \mathrm{~mm}$ thick XG196/96 type magnetic inner part covering 0.9 part.

The fact that the device has such functions greatly contributes to the fact that the electric vehicle can operate in real time.

After entering all the values, the analysis parameters were adjusted to analyze the synchronous machine. The machine is a generator, output power $3000 \mathrm{~W}$, output voltage 220 volts, rotation speed $250 \mathrm{rpm}$, outdoor air temperature $25^{\circ} \mathrm{C}$.

After analyzing the synchronous machine, a command in the form of diagrams was selected in the panel at the top of the program. With this command, we can see many characteristics of the analyzed machine in the form of diagrams.

The following list shows the values of the synchronous generator calculated in the Maxwell program.

\section{Result}

\subsection{Multipolar permanent-magnet synchronous generator design}

File: Setup1.res

GENERAL INFORMATION

Rated output power $(\mathrm{kW})$ : $\quad 3$

Number of stator slots: $\mathbf{3 6}$

Number of conductors per slot:

Limited slot fill factor (\%): $\mathbf{7 5}$

Stator slot filling factor (\%): $\mathbf{6 8 . 6 8 4 3}$

ROTOR DATA

Iron core stacking factor: $\quad \mathbf{0 . 9 5}$

Steel type: D21 $\mathbf{5 0}$

Electric pole embrace: $\mathbf{0 . 8 7 9 7 2 3}$

Magnet type:XG196 / 96

CONSTANT DATA ON A MAGNET

Residual flux density (tesla): $\mathbf{0 . 9 6}$

Coercive force $(\mathrm{kA} / \mathrm{m}): \mathbf{6 9 0}$

Maximum energy density $\left(\mathrm{kJ} / \mathrm{m}^{\wedge} 3\right): 183$

Demagnetized flux density (tesla): $\mathbf{0 . 5 3 2 4 0 9}$

Residual recoil flux density (tesla): $\mathbf{0 . 9 5 9 9 9 5}$

Recoil coercive force $(\mathrm{kA} / \mathrm{m}): \mathbf{7 6 3 , 9 6 2}$

CONSUMPTION OF MATERIAL

Density of copper armature $\left(\mathrm{kg} / \mathrm{m}^{\wedge} 3\right): \quad \mathbf{8 9 0 0}$

Density of permanent magnet $\left(\mathrm{kg} / \mathrm{m}^{\wedge} 3\right)$ : $\mathbf{7 8 0 0}$

Density of the armature core steel $\left(\mathrm{kg} / \mathrm{m}^{\wedge} 3\right): \quad \mathbf{7 8 2 0}$

Density of rotor core steel $\left(\mathrm{kg} / \mathrm{m}^{\wedge} 3\right): \quad \mathbf{7 8 2 0}$

Anchor copper weight $(\mathrm{kg})$ : $\quad \mathbf{1 3 . 9 3 0 5}$

Permanent magnet weight $(\mathrm{kg}): \quad \mathbf{6 . 9 0 7 3 1}$

Armature core steel weight (kg): $\quad \mathbf{2 7 . 3 4 1 9}$

Rotor core steel weight $(\mathrm{kg})$ : $\mathbf{6 . 8 1 8 2 2}$

Total net weight $(\mathrm{kg}): \quad \mathbf{5 4 , 9 9 8}$

Flux density between stator teeth (tesla): $\mathbf{1 . 8 3 5 5 5}$

Stator-Yoke Flux Density (Tesla): $\mathbf{0 . 0 8 1 4 7 9 4}$

Rotor-yoke flux density (tesla): $\quad \mathbf{1 . 9 0 9 4 4}$

Air-gap flux density (tesla): $\mathbf{0 . 7 6 2 2 1}$

Magnetic Flux Density (Tesla): $\quad \mathbf{0 . 7 6 7 7 5}$

Basic Induced RMS Line Voltage (V): 65.6332

Induced Voltage THD (\%): $\mathbf{2 . 2 1 4 8 1}$

Gear moment (Nm): $\quad \mathbf{0 . 1 4 7 4 5 6}$

FULL LOAD

Load Resistance (Ohm): $\mathbf{9 . 0 7 4 4 8}$

Load inductance $(\mathrm{H}): \quad \mathbf{0 . 0 1 7 9 8 1 8}$

Load line voltage $(\mathrm{V}): \quad \mathbf{6 4} 987$

Linear current RMS (A): $\quad \mathbf{3 . 0 8 7 0 2}$

RMS phase current (A): $\mathbf{3 . 0 8 7 0 2}$

RMS phase voltage (V): $\mathbf{3 8 . 1 2 2 3}$ 
Thermal load of the armature $\left(\mathrm{A}^{\wedge} 2 / \mathrm{mm}^{\wedge} 3\right)$ : 0.0766371

Specific electrical load (A / $\mathrm{mm}): \quad \mathbf{0 . 8 3 2 3 4 5}$

Armature current density $\left(\mathrm{A} / \mathrm{mm}^{\wedge} 2\right)$ :

0.0920737

Friction and wind loss (W): 12

Core loss (W): $\quad \mathbf{1 8 3 , 2 1 5}$

Copper loss in armature (W): $\mathbf{0 . 2 8 7 9 4 4}$

Total loss (W): $\quad \mathbf{1 9 5 , 5 0 3}$

Output power (W): $\quad \mathbf{7 8 . 2 5 6 9}$

Input power (W): $\mathbf{2 7 3 . 7 6}$

Efficiency (\%): $\quad \mathbf{2 8 . 5 8 5 9}$

Apparent power (VA): $\mathbf{3 5 3 . 0 5 3}$

Power Factor: $\quad \mathbf{0 . 2 2 1 6 5 8}$

Synchronous speed (rpm): $\quad \mathbf{2 5 0}$

Rated torque $(\mathrm{Nm})$ : $\quad \mathbf{1 0 . 4 5 6 9}$

Short circuit current (A): $\quad \mathbf{2 2 3 7 8 4}$

During computation, the electrical machine was analyzed by calculations in the program based on the following values: the values indicated based on the data of the parameters of the electrical machine analyzed in the following figures are given in the form of a diagram.

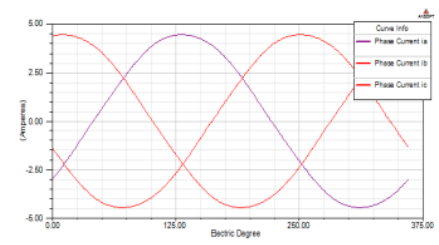

Fig. 1. Three-phase current.

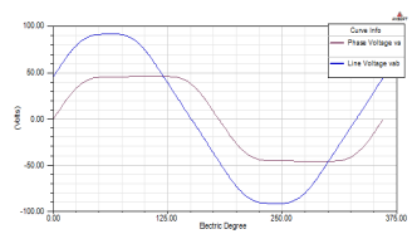

Fig. 2. Phase and line voltage.

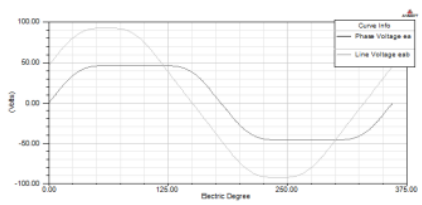

Fig. 3. Phase and line voltage.

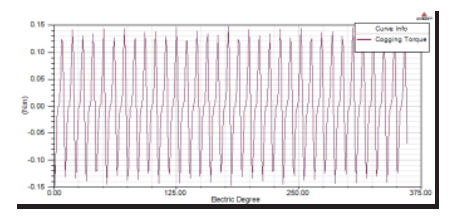

Fig. 4. Torque between stator and rotor teeth.

When these values were calculated using the formulas currently used in the design of electrical machines, they were found to correspond to the values obtained in Maxwell program.

\subsection{Analysis of an axial generator with permanent magnets in the Ansys Maxwell program}

In the experimental laboratory of alternative energy sources of the Bukhara Engineering-Technological Institute, a generator that works effectively at low water turns has been designed. The main advantage of the developed generator is that it can deliver voltage even at low rotation speeds. This result was achieved by increasing the number of pairs of generator poles. The generator has 16 pole pairs, consisting of 32 permanent magnets, and these magnets are located on the upper and lower rotors. (Figure 5) There is a fixed stator between the two rotors. The stator winding is three-phase, 4 coils in each phase. The stator windings can be connected in two ways: star or delta.

The magnetic flux generated in the generator depends on the size of the permanent magnets and the magnetic induction $[10,11]$. This expression is defined by the following formula:

$$
\Phi_{\max }=B_{q} W_{m} L_{m^{p}}
$$

The ELC formed in the generator rings is determined by the following relationship [12]:

$$
E_{f}=\frac{\sqrt{2} q_{\pi k} k_{W} \Phi_{M a x} n \pi p N}{120}=\frac{\sqrt{2} q \pi k_{W} B_{g} W_{M} L n \pi p N}{120}:
$$

where: the number of even poles of permanent magnets; the number of turns in one phase; fill factor (0.95); number of packages in one package; the rotation speed of the magnetic field; permanent magnet width; permanent magnet length; the value of the magnetic induction between two air magnetic gaps.

$$
p-q-\mathrm{k}_{\mathrm{w}}-N-n-\mathrm{W}_{\mathrm{m}}-L_{\mathrm{m}}-\mathrm{B}_{\mathrm{g}}-
$$

The magnetic flux density is explained based on Kirchhoff's law of airspace and magnetic circuit:

$$
\begin{aligned}
& \frac{B_{\mathrm{r}}}{\mu_{0} \mu_{r v \varepsilon \varepsilon}} \cdot 2 h_{M}=\frac{B_{g}}{\mu_{0} \mu_{r r v e}} \cdot 2 h_{M}+\frac{B_{Y}}{\mu_{0}} \cdot 2 g+H_{F g} l_{F e} \\
& \frac{B_{\gamma}}{\mu_{0} \mu_{r r v e}} \times 2 h_{M}=\frac{B_{g}}{\mu_{0} \mu_{r r v e}} \times 2 h_{M}+\frac{B_{r}}{\mu_{0}} \cdot 2 g k_{\text {gat }}
\end{aligned}
$$

The saturation factor of the magnetic circuit is determined from the following expression [13-15]:

$$
k_{s a t}=1+\frac{l_{F e}}{2 ? r(g+0,5 d)}
$$

where: induction of permanent magnet, height of permanent magnet, magnetic field strength of permanent magnet, distance between stator and permanent magnet, stator layer thickness.

The electromotive force generated in the generator depends on the induction of the permanent magnet and the length of the coil in the magnetic field, as well as the speed of the rotor around the stator $[16,17]$ : 


$$
\begin{aligned}
& E=l B_{g} v \\
& d E=B_{g} v d r \\
& v=v_{x}=2 \pi r n \\
& d E=B_{g}(2 \pi r n) d r
\end{aligned}
$$

Before producing generators working effectively in low speed water flow, this generator is theoretical and research is done by creating a computer virtual model $[18,19]$. If the research is successful, this generator can be used in production. The Ansys Maxwell program has great potential in generator design, virtual model creation and research on this virtual model. This program allows testing objects in an electromagnetic field. In addition, for the convenience of the user, the program offers more than a dozen models of electrical machines [20-22]. By resizing the finished models, we can create a virtual model of the generator we need.

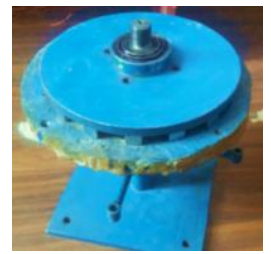

a)

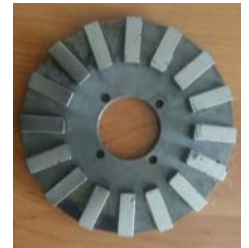

b)

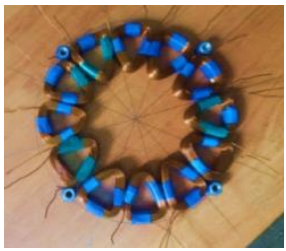

c)
Fig. 5. Experimental model of axial-flux generator (a), the rotor (b) Stator (v).

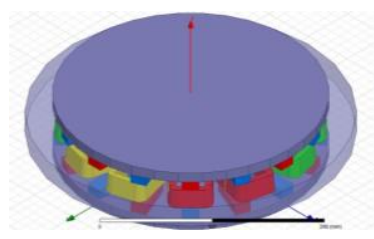

Fig. 6. General view of the axial generator in the ansys maxwell programm.

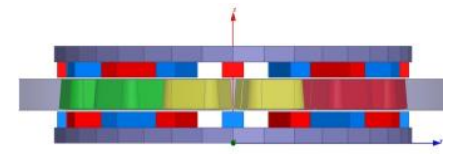

Fig. 7. Side view of the axial generator in ansys maxwell programm.

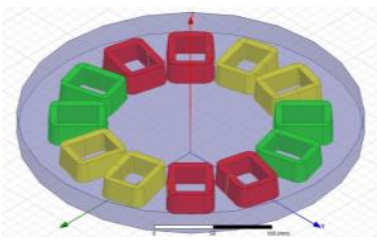

Fig. 8. Stator of the axial generator view in the ansys maxwell programm.

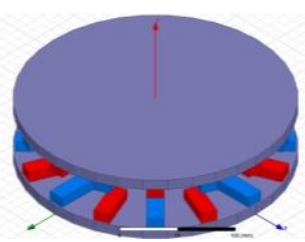

Fig. 9. Rotor of the axial generator view in the ansys maxwell programm.

In the virtual generator model in the Ansys Maxwell program, all the components used the materials provided by the program. The properties of materials in the program are equated to properties of materials in real life. For example, permanent magnets in a virtual model with a magnetic induction of $1099 \mathrm{~T}$ were chosen for permanent magnetic properties of the $\mathrm{NdFe} 35$ type. By means of standard calculations in the program, all the characteristics of the generator are checked in a magnetic field and the results are obtained. In the virtual model, the magnetic field is disconnected from the generator for a better view of the movement of power lines. The vectors of the magnetic field strength resulting from the shift and the quantitative distribution of the magnetic field are presented in the colored sections [23-24].

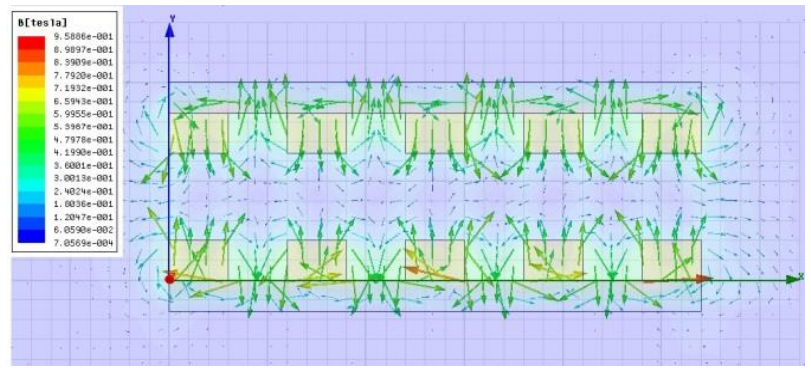

Fig. 10. The form of the magnetic field vectors in the section of the generator.

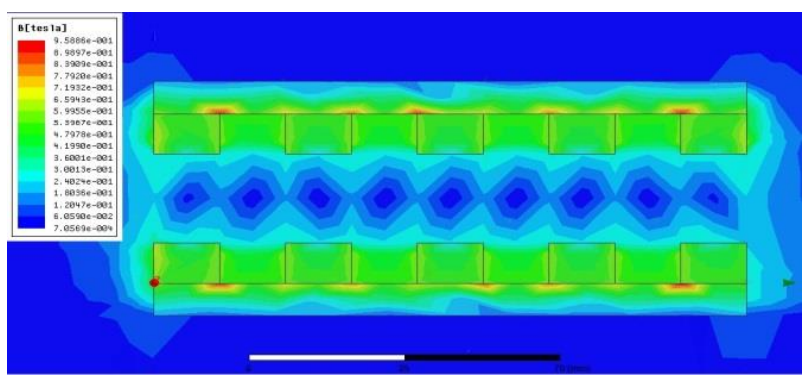

Fig. 11. The distribution of the magnetic field density in the cross section of the generator.

On Figure 10, an experimental user can easily see how the field lines of the permanent magnet are oriented in the axial generator. This creates great convenience for the user, because in real life the magnetic field is an invisible phenomenon. In figure 11 shows the leakage density of the magnetic field in the generator shell. Here, the surfaces marked in red have the lowest magnetic field strength, and the surfaces marked in blue have the lowest magnetic field strength. The energy density generated in the generator sheath is shown in fig. 12. The energy density is given by the color cross section too. 
The color density match is located at the top left of the image.

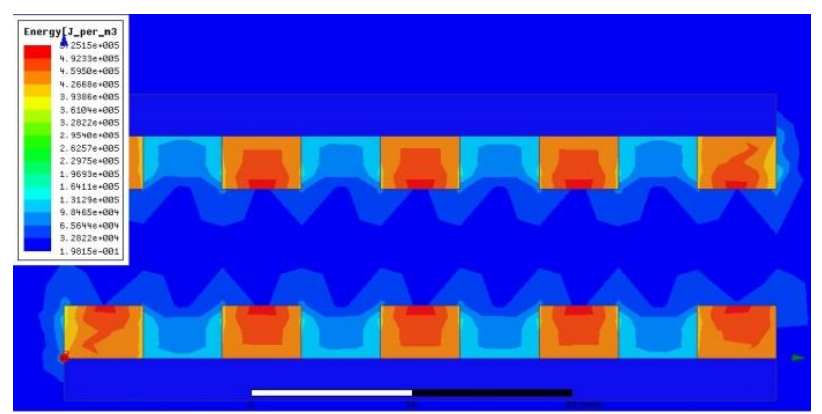

Fig. 12. Energy generation density in the section of the generator.

\section{Conclusion}

The design process of systems used in CAD/CAM/CAE programs in electrotechnical systems and innovations based on them in technological processes plays an important role in saving time and a number of other factors. In fact, for the process of obtaining optimal performance of buildings, it is necessary to repeat the process involving experiments in the design process, which in turn is carried out in practice. Because the user can see the processes that can be created through various images and animations in the virtual model. Similarly, the use of software in the development of circulating generators for micro-hydropower and wind energy services and in the creation of a new model of them is very important. The study concluded that axial generators have a compact size, high cost-effectiveness and a final cost. The use of a multipolar generator, on the other hand, is cheaper and leads to a significant increase in the size of the generator. However, the availability of materials used in the production of multipolar synchronous generators in our country, the localization of production of this generator is of great importance.

\section{References}

1. N.N. Sadullaev, A.B. Safarov, Sh.N. Nematov, R.A.Mamedov, Statistical Analysis of Wind Energy Potential in Uzbekistan's Bukhara Region Using Weibull Distribution, Applied Solar Energy, 55, 126-132 (2019) DOI: 10.3103/S0003701X19020105

2. N.N. Sadullaev, U.T. Mukhamedkhanov, Sh.N. Nematov, F.O. Sayliev, Increasing Energy Efficiency and Reliability of Electric Supply of Low Power Consumers, International Journal of Engineering Trends and Technology, 68 (12), 43-47 DOI: $10.14445 / 22315381 /$ IJETT-V68I12P208

3. N.N. Sadullayev, A.B. Safarov, Sh.N. Nematov, R.A. Mamedov, Research on facilities of power supply of small power capability consumers of Bukhara region by using wind and solar energy, Int. J. Innovative Tech-nol. Exploring Eng., 8 (9S2), 229-236 (2019)
4. N.N. Sadullayev, A.B. Safarov, Sh.N. Nematov, R.A. Mamedov, A.B. Abdujabarov, Opportunities and Prospects for the using Renewable Energy Sources in Bukhara Region, Applied Solar Energy, $56 \quad$ (4), 291-300 (2020) DOI: $10.3103 / \mathrm{S} 0003701 \mathrm{X} 20040106$

5. Na Swethithaa, D Nivedhitha, Dr.S. Allirani, Design And Analysis Of Axial Flux Permanent Magnet Machine Using ANSYS RMxprt, Iconic Research And Engineering Journals, 3 (8), 192-195 (2020)

6. M. Mirsaidov, I. Safarov, M. Teshaev, Dynamic instability of vibrations of thin-wall composite curvorine viscoelastic tubes under the influence of pulse pressure, E3S Web of Conferences, 164, 14013 (2020) DOI: 10.1051/e3sconf/202016414013

7. Y.U. Nugraha, M.N. Yuniarto, H. Herizal, D.A. Asfani, D.C. Riawan, M. Wahyudi, Design Analysis of Axial Flux Permanent Magnet BLDC Motor 5 $\mathrm{kW}$ for Electric Scooter Application, 2018 International Seminar on Intelligent Technology and Its Applications (ISITIA), Bali, Indonesia, 163-168 (2018) DOI: 10.1109/ISITIA.2018.8711225

8. W. Zhang, F. Wang, J. Guo, L. Ye, A Structure Parameter Design Method of DD Coils to Optimize Coupling Performance and Misalignment-tolerant Ability, E3S Web of Conferences, 185, 01084 (2020) DOI: 10.1051/e3sconf/202018501084

9. V. Sandeep, S. Shastri, Analysis and design of PMBLDC motor for three wheeler electric vehicle application, E3S Web of Conferences, 87, 01022 (2019) DOI: 10.1051/e3sconf/20198701022

10. S. Gumuła, M. Piaskowska-Silarska, K. Pytel, H. Noga, W. Kulinowski, Evaluation of the impact of adjusting the angle of the axis of a wind turbine rotor relative to the flow of air stream on operating parameters of a wind turbine model, E3S Web of Conferences, 14, $01016 \quad$ (2017) DOI: $10.1051 / \mathrm{e} 3$ sconf/20171401016

11. G.-P. Negreanu, I. Oprea, V. Berbece, Some design characteristics of micro steam turbines for agricultural biomass energy conversion, E3S Web of Conferences, 180, 01017 (2020) DOI: 10.1051/e3sconf/202018001017

12. R. Mustafayev, N. Yusifbayli, L. Hasanova, Matrix structure of unified mathematical model of electric AC machines at control, E3S Web of Conferences, 209, $02023 \quad$ (2020) DOI: $10.1051 / \mathrm{e} 3$ sconf/202020902023

13. G.-P. Negreanu, I. Oprea, V. Berbece, Some design characteristics of micro steam turbines for agricultural biomass energy conversion, E3S Web of Conferences, 180, $01017 \quad$ (2020) DOI: 10.1051/e3sconf/202018001017

14. E. Kurt, H. Gör, K. Çelik, Electromagnetic Analysis of an Axial Flux Permanent Magnet Generator, 2019 International Conference on Power Generation Systems and Renewable Energy Technologies (PGSRET), Istanbul, Turkey, 1-4 (2019) DOI: 10.1109/PGSRET.2019.8882685 
15. N. Radwan-Pragłowska, T. Wegiel, D. Borkowski, Modeling of Axial Flux Permanent Magnet Generators, Energies, 13 (2020) DOI: 10.3390/en13215741

16. O. Toirov, A. Bekishev, S. Urakov, U. Mirkhonov, Development of differential equations and their solution using the simulink matlab program, which calculate the self-swinging of synchronous machines with traditional and longitudinal-transverse excitation, 2020 RSES, E3S Web of Conferences, 216, $01116 \quad$ (2020) DOI: $10.1051 / \mathrm{e} 3$ sconf/202021601116

17. O. Toirov, K. Alimkhodjaev, N. Pirmatov, A. Kholbutaeva, Mathematical model to take into account the influence of saturation of the magnetic circuit on the starting characteristics of a synchronous motor, E3S Web of Conferences, 216, 01119 (2020) DOI: 10.1051/e3sconf/202021601119

18. M.K. Teshaev, I.I. Safarov, N.U. Kuldashov, M.R. Ishmamatov, T.R. Ruziev, On the Distribution of Free Waves on the Surface of a Viscoelastic Cylindrical Cavity, Journal of Vibrational Engineering and Technologies, 8 (4), 579-585 (2019) DOI: $10.1007 / \mathrm{s} 42417-019-00160-\mathrm{x}$

19. I. Safarov, M. Teshaev, E. Toshmatov, Z. Boltaev, F. Homidov, Torsional vibrations of a cylindrical shell in a linear viscoelastic medium, IOP Conference Series: Materials Science and Engineering, 883 (1), 012190 (2020)

20. E. Hüner, Optimization of axial flux permanent magnet generator by Taguchi experimental method, Bulletin of the Polish Academy of Sciences: Technical Sciences, 68 (3), 409-419 (2020) DOI: $10.24425 /$ bpasts. 2020.133378

21. A. Habib, H.S. Che, N. Abd Rahim, M. Tousizadeh, E. Sulaiman, A fully coreless Multi-Stator MultiRotor (MSMR) AFPM generator with combination of conventional and Halbach magnet arrays. Alexandria Engineering Journal, 59 (2), 589-600 (2020) DOI: 10.1016/j.aej.2020.01.039

22. E. Kurt, H. Gor, K. Celik, Electromagnetic analysis of an axial flux permanent magnet generator, 5th International Conference on Power Generation Systems and Renewable Energy Technologies, PGSRET 2019, $8882685 \quad$ (2019) DOI: 10.1109/PGSRET.2019.8882685

23. H. Asiful, H.S. Che, Design and Simulation of Axial Flux Permanent Magnet Generator for Residential Pico-Hydro Power Generation, International Conference on Intelligent and Advanced System, ICIAS 2018, $8540629 \quad$ (2018) DOI: 10.1109/ICIAS.2018.8540629

24. N. Radwan-Pragłowska, Impact of Permanent Magnets Shape and Arrangement for Selected Parameters in Coreless Axial Flux Generator, 1-6 (2018) DOI: 10.1109/ISEM.2018.8442975 